\title{
EXTERNALISMO SOCIAL: MENTE, PENSAMENTO E LINGUAGEM ${ }^{1}$
}

Jonas Gonçalves Coelho

\begin{abstract}
RESUMO: Meu objetivo é mostrar que as teses externalistas "os significados não estão na cabeça" e "os pensamentos não estão na cabeça" não implicam, necessariamente, a tese mais radical "a mente não está na cabeça". Trato dessa questão no âmbito do Externalismo Social de Tyler Burge e Lynne Baker, argumentando que a importância que esses pensadores atribuem à linguagem nas questões relativas à mente não significa, como uma leitura apressada poderia sugerir, a redução da mente à linguagem e, muito menos, a eliminação da mente. A minha conclusão é que o externalismo social linguístico não se constitui como uma estratégia eficaz de enfrentamento dos problemas da natureza da mente e de sua relação com o corpo.
\end{abstract}

PALAVRAS-CHAVE: Externalismo Social. Lynne Baker. Tyler Burge. Mente; Pensamento. Linguagem.

\section{INTRODUÇÃo}

Meu objetivo, no presente artigo, é mostrar que as teses externalistas "os significados não estão na cabeça" e "os pensamentos não estão na cabeça" não implicam, necessariamente, a tese mais radical "a mente não está na cabeça". Tal implicação, a meu ver, implícita na interpretação do externalismo linguístico funciona como uma estratégia de enfrentamento dos problemas da natureza da mente e de sua relação com o corpo. Tratarei dessa questão no âmbito de um tipo particular de externalismo, aquele que a filósofa Lynne Baker chama de

\footnotetext{
${ }^{1} \mathrm{O}$ presente artigo foi produzido a partir de pesquisa realizada durante estágio de Pós-Doutorado financiado pela FAPESP e desenvolvido no Departamento de Filosofia da Universidade de Massachusetts em Amherst, Estados Unidos, sob a supervisão da filósofa Lynne Rudder Baker.

${ }^{2}$ Professor Livre-Docente em Filosofia do Departamento de Ciências Humanas da UNESP de Bauru e do Programa de Pós-Graduação em Filosofia da UNESP de Marília.
} 
"Externalismo Social", considerando não apenas o seu próprio pensamento, mas também a abordagem de um filósofo que muito a influenciou, ou seja, Tyler Burge. Argumentarei que a importância que esses pensadores atribuem à linguagem nas questões relativas à mente não significa necessariamente, embora seus textos muitas vezes o sugiram, a redução da mente à linguagem ${ }^{3}$ e, muito menos, a eliminação da mente. Eles assumem uma posição metodológica objetivista, a qual consiste em "desconsiderar na prática" os fatores puramente subjetivos ou internos da mente, opondo-se, desse modo, à tradicional filosofia da linguagem que Hilary Putnam chama de "Solipsismo Metodológico", pelo fato de aquela "desconsiderar na prática" os fatores externos à mente, ou seja, a sociedade, o mundo natural e até o próprio corpo.

Quando os filósofos tradicionais falaram sobre estados psicológicos (ou estados "mentais"), eles supuseram o que nós podemos chamar de solipsismo metodológico. Esta é a suposição de que nenhum estado psicológico, assim propriamente chamado, pressupõe a existência de qualquer indivíduo além do sujeito a quem aquele estado é atribuído. (De fato, a suposição era de que nenhum estado psicológico pressupõe a existência nem mesmo do corpo: se P é um estado psicológico, assim propriamente chamado, então deve ser logicamente possível para uma mente "não incorporada" estar em P. Esta suposição está bem explícita em Descartes, mas está implícita em quase todo o conjunto da psicologia filosófica tradicional. (PUTNAM, 1975, p. 136).

A questão que me parece crucial, na reflexão proposta, é a compreensão que o Externalismo Social de Tyler Burge e Lynne Baker tem sobre a relação entre mente, pensamento e linguagem. O ponto a ser enfatizado é que, ao definir o pensamento em termos de atitudes proposicionais, tais como crenças, desejos e intenções, e privilegiar conceitos, como conteúdo do pensamento, o Externalismo Social preocupa-se fundamentalmente com as condições externas, naturais e principalmente sociais de individualização do pensamento ou de aplicação dos conceitos. Deixa, pois, de lado aspectos qualitativos das experiências subjetivas, os quais não seriam definidos como pensamento, embora sejam entendidos como eventos mentais internos. Essa separação entre os aspectos qualitativos da mente, por muitos tidos como primitivos e inferiores, e os aspectos proposicionais e conceituais da mente, supostamente superiores, embora contribua para ressaltar os ganhos inquestionáveis que a linguagem e a vida social trazem para o pensamento

\footnotetext{
${ }^{3}$ É o que podemos observar na maneira pela qual Lynne Baker trata do problema da causação mental, com base em seu Realismo Prático e em sua Teoria da Constituição de Propriedades. Argumentei, em um outro artigo, "A causação mental segundo o Realismo Prático de Lynne Rudder Baker" (COELHO, 2010), que a solução externalista proposta por Lynne Baker para a questão da causação mental, contra o internalismo atribuído à teoria da superveniência, apresentado por Kim, constitui-se como uma estratégia ineficaz, a qual consiste mais em um desvio do problema.
} 
individual, pode, como frisado, gerar a ideia, a meu ver equivocada, de que este é o caminho para se solucionar ou dissolver problemas filosóficos fundamentais, tais como o da natureza da mente e sua relação com o corpo, os quais resultam de abordagens internalistas e individualistas da mente.

Lembremos a paradigmática definição internalista de pensamento, isto é, a concepção de Descartes que, como se sabe, considera o pensamento em suas várias formas como a própria essência ou propriedade essencial da alma ou mente imaterial, inextensa e indivisível, irredutível à linguagem. Esta, por sua vez, é apresentada como a ferramenta do corpo material, extenso e divisível, não apenas para a expressão do pensamento da alma, mas para a testificação de sua existência. Desse modo, a concepção cartesiana da relação entre pensamento e linguagem é correlata de sua ontologia dualista, cujos problemas, em especial o da relação e união entre mente e corpo, já foram amplamente ressaltados pelos críticos de Descartes. Se, como pretendo mostrar, para o Externalismo Social a externalização do significado não significa a externalização ou eliminação da mente, essa abordagem não seria uma alternativa satisfatória de enfrentamento, mais precisamente, de desconstrução de problemas filosóficos decorrentes de uma concepção internalista da mente, em especial os problemas da natureza da mente e de sua relação com o corpo, já citados anteriormente. Sendo o caso, o valor inquestionável do Externalismo Social estaria limitado a enfatizar e elucidar a importância da linguagem para o pensamento e, principalmente, da sociedade e do mundo para a linguagem. Como ressalta explicitamente Hilary Putnam: "A filosofia tradicional da linguagem, como grande parte da filosofia tradicional, deixa de fora as outras pessoas e o mundo; uma melhor filosofia e uma melhor ciência da linguagem devem abarcar ambos" (PUTNAM, 1975, p. 193).

Com o objetivo de explicitar esses pontos, ou seja, a importância da linguagem para a mente e a irredutibilidade da mente à linguagem no âmbito do Externalismo Social, passo a seguir à apresentação das ideias de dois dos principais filósofos representantes dessa abordagem da mente, respectivamente Tyler Burge e Lynne Baker. Começarei por Tyler Burge, tratando inicialmente a sua crítica ao pensamento externalista de Hilary Putnam, cujo equívoco seria o de preservar a existência de estados psicológicos ou mentais internos ao sujeito. Mas, como também procurarei mostrar, ao defender que se podem modificar os conteúdos de pensamento de um indivíduo, alterando-se apenas o seu ambiente físico e linguístico, sem que se modifique, portanto, a sua história física, comportamental, fenomênica e funcional, Burge também estaria preservando os estados psicológicos ou mentais internos. 


\section{O ANTI-INDividualismo de Tyler Burge}

As minhas considerações sobre o Externalismo Social de Tyler Burge começarão pela sua crítica à interpretação de Hilary Putnam quanto ao experimento de pensamento por ele mesmo proposto, quer dizer, o das Terras Gêmeas.

Grosso modo, o experimento de pensamento de Putnam é exposto por Burge nos seguintes termos. Suponhamos que exista um planeta que seja uma cópia idêntica de nosso planeta Terra em todos os aspectos físicos e históricos, incluindose cópias idênticas dos habitantes da Terra - Gêmeos Terrestres -, com a única diferença de que, na Terra Gêmea, a composição química do que aqui chamamos de "água" não é H2O, mas XYZ. Apesar das semelhanças no nível macrofísico, Burge concorda com a interpretação de Putnam segundo a qual, em virtude da diferença microfísica, o líquido que na Terra Gêmea é também chamado de "água" pelos nossos gêmeos não seria na verdade água. "Eu irei apenas assumir que XYZ não é água de nenhum tipo. Água é H2O” (1982, p. 100). Daí Burge defender que, se encontrássemos na Terra o mesmo líquido da Terra Gêmea, aparentemente idêntico à água terrestre, embora quimicamente diferente, seria mais apropriado chamá-lo, por exemplo, de "tágua" ao invés de "água".

Até aqui não parece haver muitas dificuldades em relação à interpretação de Burge quanto ao experimento de pensamento das Terras Gêmeas, ou seja, considerar que os líquidos das duas Terras são distintos por terem constituição química diferente e daí referir-se a eles utilizando-se de nomes diferentes, tais como "água" e "tágua". O passo seguinte envolve, ao ver de Burge, uma semelhança e uma diferença importante entre a interpretação dos dois filósofos. Suponhamos que eu e meu gêmeo idêntico que vive na Terra Gêmea não tenhamos qualquer conhecimento de química, de tal modo que todo o conhecimento que temos a respeito da água é aquele obtido através de nossa percepção sensível macrofísica, a qual nos daria idênticos conteúdos qualitativos visuais, olfativos, táteis etc. Digamos que eu e meu gêmeo idêntico conscientemente pensemos as palavras "Existe água nas próximas 20 milhas, assim espero". Tyler Burge concorda com Hilary Putnam que as duas ocorrências da palavra "água" têm aplicação e significado diferente, isto é, $\mathrm{H} 2 \mathrm{O}$ e XYZ, ainda que eu e meu gêmeo, leigos em química, não saibamos disso. Burge não concorda com o fato de a diferença entre os gêmeos se restringir à extensão das palavras por eles usadas. Ao ver de Burge, Putnam interpreta as diferenças no uso da palavra "água" pelos gêmeos apenas como uma "diferença em extensão", não havendo entre eles diferenças em termos de sentimentos, pensamentos, monólogos interiores. Ainda de acordo com Burge, Putnam leva em conta: a) que as palavras de espécie natural, tais como "água”, são indexicais, ou seja, expressões linguísticas cuja referência mudaria de contexto para contexto, tais como, "eu", "este", "aquil", "agora" etc.; b) que as 
atitudes proposicionais dos gêmeos seriam atitudes de re, quer dizer, os res, no caso H2O e XYZ, seriam diferentes, mas os conteúdos das atitudes seriam idênticos.

Burge pensa ir mais longe do que Putnam, ao postular que a diferença entre os gêmeos não se restringe à extensão dos termos por eles empregados, mas diz respeito aos próprios conteúdos de seus pensamentos, o que significa que termos de espécie natural, tais como "água", não seriam indexicais. "A extensão de 'água', tal como interpretada em português em todos os contextos não oblíquos ${ }^{4}$, é (grosso modo) o conjunto de todos os agregados de moléculas de $\mathrm{H} 2 \mathrm{O}$, junto, provavelmente, com as moléculas individuais. Não existe de modo algum nada de indexical a respeito de 'água' no sentido costumeiro de 'indexical"' (BURGE, 1982, p. 103). Ou seja, enquanto, para Putnam, a palavra "água” teria o mesmo significado (indexicalidade), mas extensões diferentes nas duas Terras, para Burge, a palavra "água” teria significados diferentes. A palavra "água” não mudaria a sua extensão na Terra Gêmea, pelo simples fato de lá não haver água, mas apenas tágua. “O fato de os Gêmeos Terrestres aplicarem 'água' a XYZ não é um reflexo de uma mudança de extensão de uma expressão indexical com um significado lingüístico fixo (português), mas de uma mudança de significado entre uma língua, e comunidade lingüística, e outra" (BURGE, 1982, p. 105). De fato, há uma mudança no próprio conteúdo do pensamento ou estado mental dos gêmeos, conforme podemos observar nas considerações de Burge abaixo:

As diferenças não devem ser assimiladas a diferenças nas extensões de expressões indexicais com o mesmo constante significado lingüístico. Os termos relevantes não são indexicais. As diferenças, antes, envolvem a constante interpretação dos termos livre do contexto. As atribuições de atitudes proposicionais as quais colocam os termos em ocorrência oblíqua afetarão deste modo o conteúdo das atitudes proposicionais. Desde que os atos e estados mentais são individuados (parcialmente) em termos de seus conteúdos, as diferenças entre Terra e Terra Gêmea incluem diferenças nos atos e estados mentais de seus habitantes. (BURGE, 1982, p. 107).

\footnotetext{
${ }^{4}$ O que seriam essas expressões de ocorrência oblíqua? Segundo Tyler Burge, seriam expressões que não podem ser trocadas por "[...] expressões extensionalmente equivalentes de modo a manter o valor de verdade do conteúdo da sentença" (BURGE, 1979, p.76) Por exemplo, o fato de a água ser H2O não implica que alguém que pense que a água não é apropriada para beber pense que $\mathrm{H} 2 \mathrm{O}$ não é apropriada para beber. A justificativa para a tese de que água e $\mathrm{H} 2 \mathrm{O}$ não podem ser intersubstituíveis, apresentada muito rapidamente e, portanto, um tanto quanto obscura a essa altura do texto, é a seguinte: “Grosseiramente falando, a razão pela qual 'água' e 'H2O' não são intersubstituíveis [...] é que 'água' desempenha um papel ao caracterizar um ato ou estado mental diferente daquele que ' $\mathrm{H} 2 \mathrm{O}$ ' desempenharia. Neste contexto pelo menos, pensar que água não é apropriada para beber é diferente de pensar que H2O não é apropriado para beber [...]" (BURGE, 1979, p. 76).
} 
A crítica de Burge a Putnam e a diferença por este apresentada entre ambas as interpretações do experimento de pensamento das Terras Gêmeas tornam-se mais claras quando se tem em vista a distinção estabelecida por Putnam entre intensão e extensão, em termos da diferença entre "sentido estreito" e "sentido amplo" de um estado psicológico, aos quais se associariam, respectivamente, atitudes de dicto e atitudes de re. Em seu sentido estreito, o estado psicológico de uma pessoa fixaria a extensão dos termos por ela utilizados para expressar as suas atitudes proposicionais, privilegiando-se, desse modo, o estado da pessoa e desconsiderando-se individualidades externas a ela. Consequentemente, os estados psicológicos dos gêmeos, considerados em seu sentido estreito, não fixariam "as extensões dos termos que eles usam", as quais seriam diferentes, isto é, os gêmeos teriam apenas a mesma atitude proposicional de dicto.

As atitudes proposicionais não-relacionais de dicto seriam desse modo estados psicológicos no sentido estreito. Elas não exigem por generalização existencial a existência de nenhuma entidade além do sujeito (e seus conteúdos de pensamento). Atitudes proposicionais de re - pelo menos aquelas atitudes proposicionais de re nas quais o sujeito é caracterizado como estando em relação com alguma outra coisa além dele mesmo e de seus conteúdos de pensamento - parecem ser estados psicológicos no "sentido amplo". Ter atitudes de re em relação a $(d e)$ objetos outros além de si mesmo exige a existência de outros objetos além de si mesmo. (BURGE, 1982, p. 108).

Burge discorda dessa interpretação do experimento de pensamento. Argumenta, primeiramente, que os gêmeos, em suas respectivas Terras Gêmeas, não têm atitudes referentes à água com o mesmo conteúdo. De fato, na Terra Gêmea ninguém poderia ter pensamentos envolvendo o conceito de água, levando-se em conta que ninguém teve contato com água nem com alguém que tivesse tido esse contato. Afinal, lá não existe água.

Não é apenas que água não cai na extensão de qualquer dos termos dos Gêmeos Terrestres. O ponto é que nenhum de seus termos nem mesmo traduz-se para a nossa (não-indexical) palavra "água". Nenhum dicionário do Português1 para o Português daria "água" como um verbete para a palavra dos Gêmeos Terrestres. Desse modo seria um mistério como um Gêmeo Terrestre poderia partilhar qualquer das atitudes de Adam as quais envolvem a noção água. Eles não tiveram nenhum dos meios normais para adquirir o conceito. A visão correta é que eles adquiriram, por meios inteiramente normais, um conceito expresso em sua linguagem o qual mantém uma impressionante similaridade superficial com o nosso. Mas isto é diferente. (BURGE, 1982, p. 109). 
Em segundo lugar, visto que não existe água na Terra Gêmea, se o gêmeo idêntico fosse capaz de atitudes que envolvessem o conceito de água, como oposto do conceito tágua, muitas de suas crenças, diferentemente das crenças do outro gêmeo a respeito da água, seriam falsas. Por exemplo, seriam falsas as crenças de que existe água ou de que os cientistas conhecem a estrutura química da água. Mas parece não fazer sentido considerar que as suas crenças são falsas, porque elas "[...] foram adquiridas e relacionadas a seus ambientes de modos exatamente paralelos e igualmente bem sucedidos" (BURGE, 1982, p. 110) A esse respeito, a conclusão de Burge é a seguinte:

As diferenças entre as atitudes de Adam e Adam1 derivam não de diferenças no valor de verdade, mas de diferenças em seus respectivos ambientes e contextos sociais. Eles dão diferentes tipos de entidades como casos paradigmáticos de exemplos do termo. Seus usos dos termos estão embebidos em diferentes usos comunitários e tradições científicas os quais dão ao termo diferentes e constantes significados convencionais. Em contextos normais, eles podem explicar e usar o termo de modos que são informativos e socialmente aceitáveis dentro de suas respectivas comunidades. Ao fazê-lo desse modo, eles expressam diferentes noções e diferentes pensamentos com essas palavras. Seus pensamentos e afirmações têm diferentes condições de verdade e são verdade de diferentes tipos de entidades. (BURGE, 1982, p. 110).

Entretanto, Burge se coloca contra essa concepção de Putnam que preserva, ao lado da diferença entre as atitudes proposicionais relacionais, atitudes proposicionais em sentido amplo, a identidade entre as atitudes de dicto, atitudes no sentido estreito, dos gêmeos. Para Burge, os conteúdos de pensamento diferem mesmo no caso de atitudes puramente de dicto, ou seja, "[...] para saber e explicar o que uma pessoa acredita de dicto, se deve tipicamente saber alguma coisa sobre o que ela acredita de re, sobre o que os seus pares acreditam de re (e de dicto), sobre que entidades eles ostentam, sobre o que as suas palavras e a de seus pares significam, e sobre que entidades caem nas extensões de seus termos" (BURGE, 1982, p. 112). E isso significa que "[...] se pode explicar o conteúdo da atitude proposicional de uma pessoa considerando-se apenas os fatos sobre ela que são não-intencionais e não-individualísticos" (BURGE, 1982, p. 112). Conforme Burge, não existem estados psicológicos no sentido estreito, pois, tanto as atitudes de dicto quanto as atitudes de re dependem de elementos externos ao indivíduo, isto é, não apenas das entidades às quais ele se refere, mas também da comunidade social e linguística na qual está inserido.

Poder-se-ia dizer que as atitudes de dicto de Adam envolvendo a noção de água pressupõem a existência de outras entidades. As condições para individualizálas tornam essencial a referência à natureza das entidades em seu ambiente ou 
a ações e atitudes de outros na comunidade. Mesmo atitudes proposicionais puramente de dicto pressupõem a existência de entidades outras que o sujeito nesse sentido de pressuposição. Segundo esse construto, nenbuma das atitudes relevantes, de re ou de dicto, são estados psicológicos no sentido estreito. (BURGE, 1982, p. 113).

Para melhor compreender essa concepção externalista do pensamento defendida por Tyler Burge, verifiquemos a sua justificativa a partir de um de seus exemplos, o da doença artrite, apresentado em três passos no texto "Individualism and the mental". O primeiro passo consiste na descrição dos pensamentos de uma pessoa que tem crenças verdadeiras e falsas a respeito da artrite. Corretamente, essa pessoa pensa que "[...] tem artrite há vários anos, que sua artrite em seus pulsos e dedos é mais dolorosa do que sua artrite em seus tornozelos, que é melhor ter atrite do que câncer de fígado, que o endurecimento das juntas é um sintoma da artrite, que certos tipos de dores são características da artrite, que existem vários tipos de artrites, e assim por diante" (BURGE, 1979, p. 77). Incorretamente, essa mesma pessoa acredita que a sua artrite está também afetando a sua coxa. Essa crença falsa é corrigida pelo médico, que esclarece o paciente, explicitando a mesma definição de artrite que aparece nos dicionários, quer dizer, "[...] que a artrite é especificamente uma inflamação nas juntas” (BURGE, 1979, p. 77).

O segundo passo do experimento de pensamento a respeito da artrite consiste na apresentação de uma situação contrafactual, na qual a definição de artrite inclui as dores na coxa. Teríamos, então, uma pessoa nas mesmas condições físicas/fisiológicas, fenomenais não-intencionais e linguísticas, incluindo-se a sequência histórica de seus eventos e interações físicas e linguísticas com seu ambiente natural e cultural, as mesmas dores, inclusive na coxa, e o mesmo uso da palavra "artrite" aprendida, por exemplo, através da conversa com outras pessoas, e o mesmo relato para o médico. A única diferença nessa nova situação concerne ao uso da palavra "artrite" pela comunidade leiga e médica. Ela tem um uso mais abrangente, o qual inclui, além dos sintomas descritos anteriormente, várias outras doenças reumatoides, inclusive as dores na coxa. "A pessoa poderia ter tido a mesma história física e fenômeno mental não-intencional enquanto a palavra 'artrite' fosse convencionalmente aplicada, e definida para aplicar a várias doenças reumatóides, inclusive uma na coxa da pessoa, tão bem como artrite" (BURGE, 1979, p. 78).

Passemos agora ao terceiro passo do exemplo, o qual consiste na interpretação comparativa dos dois passos anteriores, isto é, na defesa de uma concepção externalista social do pensamento, a qual se confunde com a externalização dos estados e eventos mentais. Como veremos, Burge critica a tese segundo a qual o que diferencia as duas situações é apenas o uso da palavra 
"artrite" pela comunidade e não os conteúdos dos estados mentais dos indivíduos os quais permaneceriam idênticos. De acordo com o filósofo, ainda que a história física e mental não-intencional do paciente seja a mesma, na situação contrafatual, os conteúdos de suas orações mentais, ou seja, os seus pensamentos ou atitudes, como, por exemplo, crenças referentes aos conteúdos de orações da palavra "artrite", são diferentes. Isso se dá em virtude da diferença do contexto social, portanto, de diferenças que são externas ao paciente.

A palavra "artrite" na comunidade contrafatual não significa artrite. Ela não se aplica apenas a inflamação nas juntas. Nós supomos que nenhuma outra palavra no repertório do paciente significa artrite. "Artrite", na situação contrafatual, difere tanto na definição do dicionário quanto na extensão de "artrite" como nós a usamos. [...] Desse modo, os conteúdos da atitude contrafatual do paciente diferem dos conteúdos de sua atitude real [...] Em suma, as experiências qualitativas internas do paciente, seus estados e eventos fisiológicos, seus estímulos e respostas comportamentalmente descritos, as suas disposições para comportar-se, e qualquer seqüência de estados (nãointencionalmente descritos) mediadores de seu input e output - tudo isso permanece constante, enquanto que os conteúdos de sua atitude diferem, mesmo nas extensões das noções contraparte. Como nós observamos no início, essas diferenças ordinariamente resultam em diferenças nos estados e eventos mentais. (BURGE, 1979, p. 79).

Segundo Burge, se houvesse uma situação invertida, na qual o paciente tivesse uma compreensão completa e correta da palavra "artrite", ou seja, uma compreensão que excluísse a artrite na coxa, restringindo-a às juntas, mas na qual o paciente fosse corrigido pelo médico, o qual the diria que artrite pode ocorrer em outras partes do corpo, tais como músculos, tendões etc., aplicando-se assim a palavra "artrite" a todos os tipos de doenças reumatóides, a "[...] noção com a qual o médico e o paciente estariam operando em tal caso não seria a de artrite" (BURGE, 1979, p. 84). O que o experimento de pensamento pretende mostrar, em suas duas versões (a normal e a invertida), é que conteúdo de um pensamento ou evento mental, ou seja, o significado de uma noção, incompleta ou completa, depende de fatores externos ao sujeito, não das propriedades micro ou macroestruturais do mundo, mas da comunidade cultural e linguística na qual o sujeito está inserido.

O que me parece claro, nas considerações anteriores de Burge, é que sua concepção externalista não-individualista se aplica efetivamente ao pensamento definido em termos de atitudes proposicionais. Essa externalização do pensamento não implica a eliminação de aspectos internos e puramente individuais dos eventos psicológicos, isto é, ela não se aplica, como vimos, aos 
aspectos qualitativos ou fenomenais, ou seja, não-intencionais dos conteúdos do pensamento de um indivíduo. Como enfatiza ainda Burge, não se aplica também às noções ou conteúdos de pensamento envolvendo os verbos psicológicos, tais como "conhecer", "lamentar", "notar", "lembrar", "prever" e "perceber". O que distinguiria esses verbos da palavra "artrite"? A justificativa de Burge é que esses verbos sugerem uma "[...] fácil e clara distinção entre a contribuição do sujeito individual e a objetiva, "verídica" contribuição do ambiente para tornar os verbos aplicáveis" (1979, p. 85). Ainda que em tais casos a importância do ambiente natural prevaleça sobre o ambiente linguístico cultural, eles se restringiriam aos estados mentais intencionais dos indivíduos, não valendo, portanto, para os aspectos não-intencionais dos conteúdos de pensamento.

Quando uma pessoa sabe que é comum nevar em Greenland, seu conhecimento obviamente depende mais do que do modo em que a pessoa está. Ele depende de que haja realmente um bocado de neve em Greenland. O seu estado mental (a crença de que a neve é comum em Greenland) deve ser bem sucedido de um certo modo (verdadeiro). Mudando o ambiente, se pode mudar o valor de verdade do conteúdo, de tal modo que não mais se pode dizer que o sujeito conhece o conteúdo. É parte da carga de nosso argumento que mesmo estados mentais intencionais dos indivíduos tais como as crencas, os quais não têm implicações para verdade ou sucesso, não podem ser entendidos focando-se puramente em atos dos indivíduos, disposições e "interno" acontecendo. (BURGE, 1979, p. 85).

Enfim, o que estou defendendo é que já podemos entrever, nas considerações anteriores de Burge, que a sua concepção externalista do pensamento não acarreta a redução da mente a sua relação com o ambiente nem algum tipo de eliminação da mente entendida em seus aspectos puramente internos e individuais. É o que encontramos explicitamente afirmado por Burge, em seu livro recente Origins of Objectivity, ao comparar a relação entre as placas tectônicas e o ambiente geológico com a relação entre os eventos mentais e o ambiente físico e linguístico. Ele ressalta que o ser uma placa tectônica depende em parte de relações causais externas a ela, tais como outras placas, forças e massas geológicas sobre as quais escorregam ou com as quais se chocam. Mas isso não significa que se possa reduzir as placas geológicas a essas relações, considerando-se que elas têm uma estrutura interna delas independente. Algo semelhante aconteceria com os estados mentais, em sua relação com o ambiente.

O anti-individualismo defende que a natureza de muitos estados mentais depende constitutivamente de relações entre os indivíduos naqueles estados e outras coisas. A natureza de muitos estados mentais pode ser constitutivamente explicada somente por referência a um ambiente mais amplo ou subject matter. Assim como corações e placas, estados mentais constitutivamente mantém relações com coisas além deles. Assim como o coração e as placas tectônicas, 
nenhuma parte das estruturas dos próprios estados mentais está fora do indivíduo no ambiente mais amplo. Estados mentais não são eles próprios relações com o ambiente. A estrutura dos estados mentais inclui a estruturas de seus conteúdos representacionais. Essas características estruturais não são apenas constitutivas. Elas são aspectos, "partes", da natureza dos estados. O conteúdo representacional de uma crença e seus elementos estruturais são aspectos da natureza da crença (em acréscimo ao ser da crença uma crença, como oposta a esperança ou suposição). Eles são parte do que é ser um estado mental. Explicação psicológica faz uso explicativo dessas estruturas. Anti-individualismo é compatível com várias posições a respeito do problema mente-corpo. Certamente, estados mentais não flutuam livre de estados físicos underlying. Eles estão localizados onde o indivíduo que tem estes estados está. Seu loci em transações causais estão onde o senso comum e a psicologia empírica considera que eles estão. Analogias com corações e placas tectônicas valem a pena novamente manter em mente. $\mathrm{O}$ fato de que essas espécies constitutivamente dependam de relações com entidades além de seus limites é completamente compatível com corações e placas tectônicas estarem localizados no espaço. Eles não estão localizados onde as relações, ou as outras entidades com as quais eles estão constitutivamente relacionados, estão. Anti-individualismo tal como aplicado a estados mentais empíricos que são como as entidades físicas defende que tais estados constitutivamente não poderiam ser da espécie que eles são se relações causais específicas não se mantivessem entre o ambiente e o indivíduo que está nestes tipos de estados. (BURGE, 2010, p. 66).

Apesar das críticas a todas as formas de internalismo e individualismo, as quais aparecem claramente na interpretação do pensamento de Putnam, Tyler Burge, contrariamente ao que se possa inicialmente esperar, não defende nem que os significados estão fora da cabeça, nem muito menos que os estados mentais estejam fora da cabeça. E isso ele próprio focaliza literalmente, no livro mesmo livro:

O anti-individualismo per se não reivindica que os estados mentais são relações com o ambiente, ou que os estados mentais não estão na cabeça, ou que entidades no ambiente são parte do estado mental ou do conteúdo representacional dos estados. Eu rejeito essas alegações. Espécies estado-mental fundam explicações psicológicas. A maioria das relações constitutivas entre o indivíduo e o ambiente não são espécies que são citadas em explicações psicológicas ou outras explicações científicas. Ainda, eles são relevantes para uma explicação constitutiva de um indivíduo estar em um específico estado psicológico.

Estados e eventos mentais dos indivíduos não têm eles próprios uma localização que seria uma surpresa para o senso comum. Eles não estão eles próprios fora dos indivíduos. Nem eles são relações com coisas fora do indivíduo. Versões do anti-individualismo clamam que os estados mentais não estão na cabeça, ou são relações com o ambiente. Eu vejo essas versões como incorretas [...] nada no anti-individualismo - ou no que o próprio Putnam 
argumentou com sucesso - implica que estados ou eventos marcados por conteúdo representacional não possam estar na cabeça. (BURGE, 2010, p. 64).

A partir das reflexões anteriores sobre o Externalismo Social de Tyler Burge, eu gostaria de chamar a atenção para dois aspectos os quais que me parecem fundamentais. Primeiro, o filósofo trata fundamentalmente dos conteúdos da mente e não da sua forma, ou seja, ele defenderia que a atividade pensante é própria do sujeito, ainda que os seus conteúdos dependam do ambiente físico e linguístico. Segundo, embora a sua definição de pensamento não inclua todo o conjunto de atividades mentais, isso não significa que a sua concepção de mente exclua aspectos puramente internos, já que, como vimos, preservam-se tanto as experiências subjetivas qualitativas relacionadas ao mundo externo, quer dizer, as várias formas de percepção sensível, quanto as experiências qualitativas concebidas como puramente subjetivas, tais como dores e sentimentos em geral.

Para desenvolver esses aspectos e, com base neles, tecer algumas considerações a respeito dos limites do Externalismo Social para o enfrentamento dos problemas da natureza da mente e da relação mente, tratarei a seguir do pensamento da filósofa Lynne Baker, cujas ideias, como sublinhamos, foram bastante influenciadas por Tyler Burge.

\section{O ANTI-INDIVIDUALISMO DE LYNNE BAKER}

Terei em vista, inicialmente, as definições de Externalismo e Externalismo Social apresentadas por Lynne Baker, no texto "Social Externalism and FirstPerson Authority". Começarei analisando a definição mais geral: "Externalismo é a tese segundo a qual os conteúdos de pensamento são frequentemente determinados em parte por várias características do ambiente do pensador" (BAKER, 2007b, p.287). Primeiramente, gostaria de chamar a atenção para o uso dos termos "frequentemente" e "em parte", os quais parecem amenizar a radicalidade de uma abordagem externalista da mente. A presença desses termos na definição de externalismo sugere que nem todos os conteúdos de pensamento são determinados pelas características do ambiente do pensador. Se for o caso, deparamo-nos com as seguintes questões: quais conteúdos de pensamento não proviriam do ambiente? Se não for do ambiente, qual seria a origem desses pensamentos? Como não encontramos nos textos de Lynne Baker uma resposta explícita para essas questões, acredito que tais exceções não existem de fato, ou que não seriam suficientemente relevantes para serem consideradas. $\mathrm{O}$ uso daqueles termos poderia ser então interpretado como medida de precaução ou hesitação da filósofa em apresentar uma concepção externalista radical, que 
incluísse algumas experiências subjetivas qualitativas, tais como alegria, tristeza, dor etc. Contudo, como veremos posteriormente, essa não é uma questão muito simples, pois, de acordo com o externalismo social, tais experiências não são caracterizadas como tipos de pensamentos, os quais são descritos em termos de atitudes proposicionais. Deixando provisoriamente essa questão em aberto, passo agora à análise da definição de externalismo social exposta por Lynne Baker, no mesmo artigo.

Como vimos anteriormente, o externalismo é apresentado como uma concepção segundo a qual os conteúdos de pensamento de uma pessoa são determinados pelo seu ambiente. Nesses termos, a questão fundamental passa a ser a seguinte, formulada por Lynne Baker de três maneiras distintas: como "[...] as características do ambiente podem contribuir para o conteúdo do pensamento de uma pessoa”? (BAKER, 2007b, p. 288); “[...] como os conteúdos de pensamento são individuados"? (BAKER, 2007b, p. 288); quais "[...] são as condições sob as quais uma pessoa tem um pensamento com um conteúdo particular?" (BAKER, 2007b, p. 288). O elemento comum dessas três questões é a busca pelas condições responsáveis pelo conteúdo específico de cada pensamento, ou seja, o que faz com que um pensamento seja diferente de outro pensamento ou o que determina a sua "identidade", termo usado pela filósofa, como veremos a seguir.

A resposta a essas questões advém de uma abordagem teórica a qual Lynne Baker chama de Externalismo Social, por ela definida nos seguintes termos: "A maioria dos conteúdos de pensamento de uma pessoa é determinada (em parte) pelas práticas sociais e lingüísticas da comunidade da pessoa" (BAKER, 2007b, p. 288). Observemos novamente que a filósofa usa as expressões "maioria" e "em parte", a cujas dificuldades já nos referimos. O que gostaria de ressaltar, primeiramente, nessa definição de Externalismo Social é o fato de que o ambiente tido por fundamental para o conteúdo do pensamento de uma pessoa é o ambiente sociocultural no qual ela está inserida, é a prática linguística de sua comunidade. Tal prática, como veremos, faz a mediação com outro ambiente no qual toda pessoa está imersa, isto é, o ambiente natural. Como procurarei mostrar, o Externalismo Social estabelece uma relação indissociável entre pensamento, linguagem e natureza, privilegiando consideravelmente a linguagem. Vejamos como essa relação é apresentada por Lynne Baker. Tratarei inicialmente da relação entre pensamento e linguagem. A seguir, focalizarei a relação entre linguagem, pensamento e ambiente cultural. Por fim, focarei na relação entre pensamento, linguagem e ambiente natural. 
A relação entre pensamento e linguagem é, como se pode observar na citação a seguir ${ }^{5}$, uma relação intrínseca, ou seja, pensamento e linguagem estão intimamente ligados.

A identidade de um pensamento depende da identidade de seu conteúdo proposicional [...] Eu usarei a palavra "conceito" para referir aos itens constitutivos dos conteúdos proposicionais e eu usarei a palavra "pensamentos" para qualquer estado mental com conteúdo proposicional, por exemplo, crenças, desejos, intenções, esperanças, medos, etc. Eu direi que pensamentos contêm ou são compostos por conceitos. (BAKER, 2007b, p. 288).

Para melhor entender a enunciada relação entre pensamento e linguagem, três aspectos devem ser considerados. A partir das citações anteriores, examinarei a definição de pensamento; a seguir, a definição de conceito; e, por fim, a relação pensamento e conceito. Quanto à definição de pensamento, três aspectos me parecem relevantes. Primeiro, o que significa dizer que a "[...] identidade do pensamento depende da identidade de seu conteúdo proposicional"? Seria o mesmo que dizer que o conteúdo do pensamento depende do conteúdo proposicional? Observemos que, ao apresentar como exemplos de conteúdo proposicional as crenças, os desejos, as intenções etc., Lynne Baker não diferencia a noção de "conteúdo proposicional" da noção de "atitude proposicional", o que entendo ser importante para se pensar na diferença entre modos - atitudes - e os próprios conteúdos do pensamento. Essa diferença parece estar implícita no próprio texto da filósofa, quando ela se refere aos conceitos como os "[...] itens constitutivos dos conteúdos proposicionais". Sendo o caso, parece não haver problema em responder às questões colocadas no início deste parágrafo, com a interpretação de que o pensamento em sua forma e conteúdo depende da forma e conteúdo proposicionais.

O segundo aspecto é o que trata da relação entre o pensamento, caracterizado como um estado mental, e o conteúdo proposicional. Ao ressalvar que usa a palavra "pensamento" para se referir a "[...] qualquer estado mental com conteúdo proposicional", estaria Lynne Baker defendendo que existem estados mentais que não têm conteúdo proposicional e que, portanto, não são

\footnotetext{
5 A relação entre pensamento e linguagem é exposta nos mesmos termos, no texto "First-Person Externalism", escrito no mesmo ano por Lynne Baker: "Deixe a palavra 'pensamentos' referir a qualquer estado mental com conteúdo proposicional - crenças, esperanças, medos, desejos, intenções e assim por diante, e deixe 'conceitos' referir aos itens constitutivos dos conteúdos proposicionais [...] Podemos então dizer que os pensamentos contêm ou são compostos por conceitos [...] $\mathrm{O}$ termo 'conceito' em meu uso não carrega muito peso teórico. Eu estou simplesmente usando o termo a fim de identificar os constituintes dos pensamentos, os itens que compõem os conteúdos dos pensamentos e determinam a identidade dos pensamentos [...] A fim de se ter um pensamento contendo um conteúdo particular, se deve ter o conceitos" (BAKER, 2007a, p. 156).
} 
pensamentos? Se for o caso, quais seriam esses estados mentais? Como exemplos de pensamento, Lynne Baker cita, como vimos, as crenças, os desejos, as intenções, as esperanças, os medos etc. Qual seria o estatuto, por exemplo, das percepções e sentimentos como alegria, tristeza e dor, já referidos anteriormente? Seriam eventos mentais, mas não pensamentos, ou seja, estados irredutíveis ao físico, mas, conforme os termos da filósofa, sem conteúdo proposicional? Vejamos se é possível explicitar esse ponto com base na definição de "conceito" e de sua relação com o pensamento propostos por Lynne Baker, terceiro aspecto da relação entre pensamento e linguagem a ser considerado.

Os conceitos são apresentados como os constituintes fundamentais do pensamento. Já notamos que os conceitos são definidos como os "itens" que constituem os conteúdos proposicionais e, consequentemente - considerando-se que "[...] a identidade de um pensamento depende da identidade de seu conteúdo proposicional", - os conceitos constituem o conteúdo dos pensamentos. Porém, afirmar que o conceito é o "item" constitutivo do pensamento não é dizer tudo o que é relevante a seu respeito, isto é, tendo em vista a sua relação com o conteúdo do pensamento, deve-se explicar as condições determinantes de sua posse e conteúdo, as quais, como veremos a seguir, envolvem o ambiente sociocultural.

A esse respeito, Lynne Baker enfatiza que o que "[...] é significante a respeito dos conceitos (além do fato de que eles compõem pensamentos) é que eles têm condições de aplicação: definitivamente um conceito aplica-se a algumas coisas e definitivamente não se aplica a outras coisas" (BAKER, 2007b, p. 288). A esse respeito, conforme Lynne Baker, ter um conceito é ser capaz de aplicá-lo corretamente em uma ampla variedade de casos, ainda que em alguns desses casos o conhecimento das condições de aplicação seja parcial. Essa tese é explicada e justificada no contexto da abordagem externalista social, sendo inicialmente apresentada esquematicamente pela filósofa nos seguintes termos: "Para qualquer $\mathrm{S}$, se $\mathrm{S}$ tem $\mathrm{C}$ [o conceito $\mathrm{C}$ ], segue-se que, mantendo-se constantes a história física e os estados internos físicos de $\mathrm{S}$, se $\mathrm{S}$ estivesse em uma comunidade com práticas sociais e lingüísticas relevantemente diferentes, S não teria C [...] se alguém tem ou não um conceito C depende das práticas sociais e lingüísticas de sua comunidade" (BAKER, 2007b, p. 289). Ou, de forma mais abrangente:

Para ter um conceito particular, deve-se ser capaz de aplicá-lo corretamente (a maior parte do tempo). (Mesmo conceitos vazios como *unicórnio* podem ser aplicados corretamente - em contextos lingüísticos nos quais animais míticos estão sendo considerados, ou em contexto pictóricos de desenhos de pequenos animais com chifres em suas testas.) Conceitos têm condições de aplicação: um conceito definitivamente aplica-se a algumas coisas e definitivamente não se aplica a outras coisas. Completo domínio da aplicação dos conceitos não e necessário para se ter um conceito [...] S tem um conceito $\mathrm{C}$ se e somente se (i) 
S e capaz de aplicar C corretamente em um significante numero de casos; e (ii) $\mathrm{S}$ tem alguma (talvez parcial) compreensão das condições e conseqüências da aplicação de C. (BAKER, 2007a, p. 156).

Vemos, assim, que as práticas linguísticas e sociais seriam os determinantes para a posse ou não de um conceito, e essa tese não se restringe, como se poderia pensar à primeira vista, apenas ao que chamaremos de conceitos de "espécie cultural", ou seja, os conceitos sociais, políticos ou legais, mas também ao que os filósofos chamam de conceitos de "espécie natural". Procurarei ilustrar essa tese e apontar algumas de suas dificuldades, a partir da apresentação sucinta de alguns dentre os exemplos propostos por Lynne Baker. Começarei por um conceito de espécie natural ${ }^{6}$, o conceito de rocha.

Suponhamos que um sujeito "A" acredite que rochas são pesadas e que " $A$ " expresse a sua crença em português, no contexto de sua comunidade linguística "X", dizendo "Rochas são pesadas". Suponhamos, também, que exista outra comunidade linguística "Y" que tenha uma palavra fonologicamente indistinguível da palavra "rocha" pronunciada por " $\mathrm{A}$ " na comunidade linguística "X", com a diferença de que na comunidade linguística "Y" a palavra "[...] inclui somente pedras grandes encontradas em terras secas (em campos ou montanhas) e não pedras grandes encontradas perto de ou em leitos de água" (BAKER, 2007b, p.290). A tese do externalismo social é que, se "A" profere a palavra "rocha" nas duas comunidades linguísticas, "A" não cometeria um erro conceitual na comunidade linguística " $\mathrm{X}$ ", mas, se fosse trazido repentinamente para a comunidade linguística " $Y$ " e aí utilizasse a palavra que soa como "rocha" - sem que tivesse tempo, portanto, para apreender a diferença entre as duas palavras nas duas diferentes comunidades -, "A" cometeria um erro conceitual na comunidade linguística "Y". Além disso, e por causa disso, na comunidade linguística "X", "A" teria a crença "Rochas são pesadas", mas não teria a mesma crença na comunidade " $\mathrm{Y}$ ”. E a diferença entre as duas sentenças, a qual daria a elas valores de verdade distintos, não estaria nos respectivos sons proferidos, os quais, como vimos, seriam idênticos, mas sim em suas referências distintas, em suas diferentes condições de aplicação 7 . Desse modo, preservando-se a mesma história física e a mesma organização e constituição corporal/cerebral de "A" no proferimento da mesma palavra - sonoramente falando - nas comunidades "X" e "Y", A teria diferentes crenças. Afinal, os conceitos seriam diferentes.

\footnotetext{
${ }^{6}$ Apresento o exemplo, referindo-me à língua portuguesa, ao invés da língua inglesa citada pela filósofa.

7 Pode-se conceber facilmente que, no âmbito de uma mesma comunidade linguística, possa haver duas palavras diferentes correspondentes às duas diferentes referências ou condições de aplicação.
} 
"Os conceitos expressos desse modo diferem nas duas comunidades" (BAKER, 2007b, p. 290). Do que foi exposto anteriormente, pode-se concluir que, se "A" fosse criado na comunidade linguística " $\mathrm{Y}$ ", na qual teria aprendido a usar a palavra fonologicamente indistinguível da palavra "rocha", ao usá-la obedecendo às "condições de aplicação", " $\mathrm{A}$ " não estaria cometendo nenhum erro conceitual. Preservar-se-ia, desse modo, o valor de verdade de sua crença "Rochas são pesadas". Moral da história: sentenças fonológica e sintaticamente idênticas podem expressar diferentes crenças.

O conceito utilizado no exemplo anterior pode ser tomado como um conceito de espécie cultural, ainda que, segundo Lynne Baker, intuitivamente não o seja. Entendo que não é o caso no momento, por não ser relevante para a questão que considero central, discutir em que medida o exemplo proposto é de espécie cultural ou de espécie natural. Afinal, a filósofa defende, como veremos, que todos os conceitos são de certo modo de espécie cultural. Enfoco, a seguir, um exemplo costumeiramente citado como sendo de espécie natural. Lembro que estou apresentando o exemplo de Lynne Baker com certa liberdade, de sorte que me permita exprimir mais claramente a maneira como o compreendo. Trata-se de entender, a partir do externalismo social, os conceitos "limestone" e "sandstone", os quais traduzirei respectivamente por "calcário" e "arenito". Apenas para que o exemplo possa servir ao propósito de ilustrar a abordagem externalista social da mente, suponhamos que calcário e arenito tenham ambos uma cor amarelada e sejam também fisicamente idênticos em outras características macrofísicas, de tal maneira que o observador comum não consiga distingui-los pela visão natural, mas que sejam quimicamente distintos, ou seja, que calcário seja carbonato de cálcio (CaCO4) e que arenito seja dióxido de silicone (SiO2).

Considerarei, agora, duas situações distintas. Primeira situação: um sujeito "A" foi criado e vive na comunidade linguística "X". "A" fala a língua dessa comunidade, na qual existe calcário, mas não arenito. Embora nunca tenha visto calcário pessoalmente, "A" conhece tudo a respeito de suas propriedades macrofísicas não conhece, portanto, as suas propriedades químicas. Adquiriu esse conhecimento por meio dos livros e dos colegas de escola. Assim, "A" tem o conceito calcário, isto é, " $\mathrm{A}$ " "[...] é capaz de aplicar corretamente o conceito *calcário* e ' $\mathrm{A}$ " "tem uma compreensão (talvez parcial [já que não tem o conhecimento da composição química]) das condições de aplicação de *calcário*” (BAKER, 2007b, p. 290).

Segunda situação: o sujeito "A" foi criado e vive em outra comunidade linguística, "Y". A fala a língua dessa comunidade, na qual não existe calcário, mas apenas arenito. Embora nunca tenha visto arenito pessoalmente, "A" conhece tudo a respeito de suas propriedades macrofísicas - não conhece, portanto, as suas propriedades químicas. Adquiriu esse conhecimento por meio dos livros e 
dos colegas de escola. Assim, "A" tem o conceito arenito, ou seja, "A" "é capaz de aplicar corretamente o conceito *arenito* e "A" "[...] tem uma compreensão (talvez parcial [já que não tem o conhecimento da composição química]) das condições de aplicação de *arenito*" (BAKER, 2007b, p. 290).

Imagine-se agora o seguinte: a comunidade linguística "Y" é uma cópia idêntica da comunidade linguística " $\mathrm{X}$ ", tanto em relação às pessoas existentes, sua história física e cultural, quanto em relação à aparência e constituição física da matéria e objetos existentes, mas com uma única diferença - a existência de arenito, ao invés de calcário. Lembremos que essa diferença existe apenas no nível microfísico, constituição química, não sendo, portanto, identificada por "A", que conhece arenito apenas por suas propriedades macrofisicas. Pensemos, também, que a palavra "calcário" tenha uma cópia fonologicamente idêntica em "Y", a qual é utilizada para "designar" arenito. Segundo o externalismo social, " $\mathrm{A}$ " não teria em "Y" o conceito "calcário" e sim o conceito "arenito". Uma palavra fonologicamente idêntica teria referência distinta nas duas comunidades. A conclusão, conforme os termos de Lynne Baker, é a seguinte:

O conceito *alcário* é um conceito diferente do conceito *arenito*. Os dois conceitos têm condições de aplicação inteiramente diferentes. Variando somente a comunidade de A, nós podemos variar o conceito que A tem *calcário * ou *arenito* sem mudar nenhum de seus estados internos ou nenhuma das pessoas ou coisas com as quais ele interage ou quaisquer das maneiras não intencionais com as quais ele interage. A nem mesmo tem falsas crenças sobre as condições de aplicação de um ou de outro dos conceitos *calcário* ou *arenito*; ele não tem falsas crenças a respeito da composição química de cada um deles desde que ele não tem crenças sobre composição química - não mais do que nossos ancestrais os quais tinham o conceito de *calcário*. (BAKER, 2007b, p. 291).

A abordagem externalista social do pensamento/conceito tem sido objeto de muitas críticas e objeções, grande parte delas provenientes de concepções internalistas. Contudo, em seu texto "Social Externalism and first-person authority", Lynne Baker ignora essas críticas internalistas, apresentando uma única objeção ao exemplo proposto, uma objeção externalista, que chamaremos aqui "externalismo naturalista". A objeção consiste em afirmar que os conceitos *calcário* e *arenito* são conceitos de espécie natural e, portanto, que a diferença entre eles não depende das práticas linguísticas da comunidade, mas sim de uma diferença existente na própria natureza, tese atribuída a Hilary Putnam, a partir de sua interpretação do experimento de pensamento das Terras Gêmeas. 
Lynne Baker propõe duas respostas a essa objeção. Primeira resposta: a filósofa salienta que no experimento de pensamento, tal como foi apresentado inicialmente, "A" adquiriu os conceitos de *calcário* e *arenito* nas práticas sociais e linguísticas, ou seja, através dos livros e dos colegas da escola, não tendo tido qualquer tipo de interação direta com calcário e arenito. Essa resposta me parece insatisfatória, pois, ainda que na situação particular esboçada possamos considerar que " $\mathrm{A}$ " não tenha interagido diretamente com tais elementos da natureza, nada impede que outros sujeitos, por exemplo, aqueles que produziram os livros consultados por "A", tenham tido essa interação. Poderíamos sublinhar que, se esse fosse o caso, os conceitos "calcário" e "arenito" seriam de "espécie natural" e não de "espécie cultural"? Não é o que pensa Lynne Baker. A autora afirma, como segunda resposta à objeção externalista naturalista, que "[...] a existência de amostras de espécie natural não é nunca suficiente para alguém ter o conceito da espécie. Práticas sociais e linguísticas são os intermediários requeridos para que se compartilhem os conceitos em qualquer situação" (BAKER, 2007b, p. 291). De acordo com a filósofa, se, por um lado, as práticas sociais e linguísticas incluem as características do ambiente aos quais elas se referem em suas condições de aplicação, por outro, a mera existência dos elementos naturais calcário e arenito na natureza não seria suficiente para a existência dos conceitos "calcário" e "arenito" em uma comunidade que vive nesse ambiente.

É nesse mesmo sentido que Lynne Baker interpreta outro exemplo, o do uso dos conceitos de "golfinho" e "tubarão", e refuta objeções semelhantes às anteriores. Contra o Externalismo Social, poder-se-ia alegar que ter ou não ter os conceitos de "golfinho" ou de "tubarão" depende apenas das diferenças entre as espécies naturais e não de práticas linguísticas. Desse modo, se uma pessoa solitária - a "solitária Jô" - vivesse numa ilha cercada por tubarões, ela teria o conceito de "tubarão", e, se fosse cercada por golfinhos, ela teria o conceito de "golfinho". Contra essa tese, Lynne Baker defende, primeiramente, que em geral as pessoas não adquirem esses conceitos a partir da interação direta com golfinhos ou tubarões e sim das práticas linguísticas e sociais de sua comunidade. Além disso, a existência de amostras de espécie natural não seria suficiente para se ter o conceito daquela espécie (2007a, p. 160). Em consonância com essa ideia, a filósofa afirma que a pessoa solitária na ilha não adquiriria os conceitos de "tubarão" ou de "golfinho". Lynne Baker argumenta, grosso modo, que a Solitária Jô não poderia ter os conceitos de "tubarão" ou de "golfinho", na medida em que a posse desses conceitos depende da comunidade na qual se está inserido. $\mathrm{Na}$ ausência de uma comunidade linguística, a Solitária Jô, que não tem nenhuma linguagem, como o exemplo sugere, não teria como diferenciar o uso correto ou incorreto de tais conceitos, condição fundamental para a posse de um conceito, 
ou seja, ela não teria como fixar a extensão do conceito, o qual seria estabelecido pela comunidade linguística.

Ninguém tem um conceito a não ser que haja uma diferença entre aplicá-lo corretamente e aplicá-lo incorretamente. Na ausência de uma comunidade, não há nada que possa tornar correto aplicar o suposto conceito de tubarão da Solitária Jô como oposto a tubarões cabeça-de-martelo ou tubarões-ougolfinhos. Não há nada no ambiente da Solitária Jô que tornaria incorreto aplicar seu suposto conceito a golfinhos, ou impedi-la de aplicá-lo a tubarões tigre-do-mar. Apenas a familiaridade da Solitária Jô com tubarões junto com outras criaturas do mar dificilmente dá a ela o conceito de *tubarão*. Existem 350 espécies de tubarões que são radicalmente dessemelhantes entre si [...] Eu concordo que ser um membro de uma determinada espécie natural independe das práticas sociais e lingüísticas; mas este ponto e irrelevante. A questão não diz respeito a ser um membro de uma espécie natural; ela diz respeito à aquisição do conceito de uma espécie-natural, *tubarão*. O que fixa a extensão de um suposto conceito de uma pessoa em isolamento, uma pessoa sem uma linguagem natural como o inglês? $\mathrm{Na}$ ausência da linguagem, o que faria com que qualquer dos eventos mentais ou vocalizações da Solitária Jô expressassem o conceito *tubarão* - como oposto a *tubarão cabeça-de-martelo*, *tubarão tigredo-mar*, *peixe* ou milhões de outras espécies naturais as quais um tubarão particular pertence? Em virtude do que qualquer pensamento da Solitária Jô conteria o conceito *tubarão* - como oposto aos conceitos *tubarão cabeça-demartelo* ou qualquer dos alternativos? (BAKER, 2007a, p. 160).

O ponto-chave na argumentação de Lynne Baker é o papel que a "linguagem pública" tem, no estabelecimento dos conceitos. Sem essa linguagem, ou reduzida à possibilidade de uma definição ostensiva, não se teriam os "recursos descritivos" necessários para fixar a extensão do conceito de uma espécie de tubarão e diferenciá-lo das outras 350 espécies, por exemplo. E por não ter também o conceito abstrato de "espécie natural", a Solitária Jô não teria como referir-se a uma espécie de tubarão, o que seria possível, se "[...] houvesse a mediação das práticas sociais e lingüísticas [...]” (BAKER, 2007a, p. 160). Lynne Baker conclui, ressaltando a importância da linguagem para o conteúdo do pensamento ou "vida interior" de uma pessoa:

Não é como se a Solitária Jô tivesse uma rica vida interior na qual ela pode notar como as coisas parecem para ela e então inquirir como elas realmente são. Nós sabemos muito pouco sobre o caráter da vida interior da Solitária Jô, mas é exatamente uma fantasia cartesiana supor que ela se parece com a nossa [...] sem a mediação das práticas sociais e lingüísticas, não há nenhum fato sobre a questão de se o som ou marca de uma pessoa expressa um conceito com a extensão de *tubarão*. (BAKER, 2007a, p.160). 
À primeira vista, as considerações anteriores sugerem que, ao enfatizar a importância da comunidade linguística para a posse de conceitos, Lynne Baker estaria postulando que a "solitária Jô" teria vida interior extremamente empobrecida pelo fato de ela não pensar, isto é, de não ter crenças, desejos ou intenções, as quais não existiriam sem conteúdo, sem conceitos: “[...] ter os conceitos é importante porque a classe de pensamentos que alguém pode entreter é limitada pelos conceitos que ele tem" (BAKER, 2007a, p. 161). Nesse sentido, a filósofa estaria reduzindo a vida interior da "solitária Jô", quando muito, a experiências qualitativas não muito diferentes daquelas que poderiam ser atribuídas a alguns tipos de animais. Essa interpretação do pensamento de Lynne Baker parece excessiva diante da distinção que ela estabelece entre "condições de individuação" e "condições de aquisição" de um conceito. A esse respeito, a filósofa argumenta, sem maiores esclarecimentos, que as práticas linguísticas são condições essenciais apenas para a aquisição de conceitos, aspecto que mais a interessa e do qual ela se ocupa, mas não para a sua individuação:

Eu admito que os conceitos *tubarão* e *golfinho* são individuados independentemente de práticas linguísticas e sociais. Mas o Externalismo Social, como eu o tenho formulado, não está preocupado com como os conceitos são individuados, mas antes com as condições sob as quais uma pessoa tem um certo conceito (e os pensamentos contendo-o). $\mathrm{O}$ fato de que um conceito é individuado independentemente de práticas linguísticas e sociais é irrelevante para o fato de ele ser ou não um conceito Externalista Social. Um conceito é um conceito Externalista Sócia, se alguém o tem depende de práticas sociais e linguísticas, a despeito de como o conceito é individuado. (BAKER, 2007a, p. 161).

Como entender essa distinção, em especial, o que ela concebe como "condições de individuação" de um conceito? Em outro texto, essa distinção também aparece, embora em termos um pouco diferentes, mas não mais esclarecedora.

Externalismo é usualmente entendido como uma tese sobre como conteúdos de pensamento são individuados. Existem duas maneiras de entender essa tese - ou antes dois modos pelos quais as características do ambiente podem contribuir para o conteúdo do pensamento de uma pessoa. A primeira interpretação foca no pensamento: quais são as condições sob as quais um pensamento tem o conteúdo particular que ele tem? A segunda interpretação foca no pensador. Quais são as condições sob as quais uma pessoa tem um pensamento com um conteúdo particular?. (BAKER, 2007b, p. 288).

As condições de aquisição de um conceito se confundem com as condições de sua aplicação, ou seja, o significado ou conteúdo de um conceito adquirido por cada pensador individual, no âmbito de uma comunidade linguística, é determinado 
pelo modo como essa comunidade o utiliza. Já a questão da individuação, da qual a filósofa não se ocupa, parece-me importante justamente por apontar para condições primeiras sem as quais o pensamento também não seria possível, quer dizer, condições necessárias, ainda que não suficientes, para o surgimento de um conceito no âmbito de uma comunidade linguística. Trato de condições primeiras, considerando que todo conceito tem uma história, ou seja, apareceu primeiramente em algum momento no âmbito da comunidade. Não me parece que tenham que ter surgido coletivamente. E o que, a meu ver, é o mais importante, não me parece razoável supor que os conceitos, por mais abstratos que sejam, possam ser adquiridos sem experiências qualitativas individuais, por exemplo, percepções externas ou internas, tidas como não conceituais ou como não pensamento pelo Externalismo Social. Lembrando toda a tradição empirista na Filosofia, como seria possível haver conceitos de dor, de cor, sem experiências subjetivas que ancorem esses conceitos, ainda que eles não se reduzam ou não se confundam com elas? A questão é se seria possível ter as condições de aplicação que tornam possível a aquisição individual dos conceitos "grama" e "verde", tal como aparecem na citação que segue, sem que o indivíduo tenha as experiências qualitativas individuais. Poderiam essas experiências ser incluídas dentre as "condições de individuação" de um conceito, necessárias para a sua aquisição, sendo essa, por sua vez, testificada por sua apropriada aplicação, tal como descrita abaixo.

Eu direi que alguém "tem" um conceito se alguém é capaz de entreter pensamentos que têm o conceito como um constituinte. Se alguém é capaz de entreter o pensamento ${ }^{*}$ A grama é verde* esse alguém tem os conceitos $*_{\text {grama* }}$ e $^{*}$ verde*. Reconhecidamente ${ }^{*}$ grama* e ${ }^{*}$ verde* são ambos conceitos vagos pelo fato de as condições de aplicação de cada um deles deixar casos fronteiriços. No entanto, existem algumas condições sob as quais cada um aplicase definitivamente e algumas condições sob as quais cada um definitivamente não se aplica. Para se ter um conceito no sentido relevante se deve ser capaz de aplicá-lo corretamente em uma variedade de contextos. (BAKER, 2011, p. 8).

O que procurei mostrar, nas considerações anteriores sobre o pensamento de Lynne Baker, que também vale para Tyler Burge, foi que, embora o Externalismo Social chame a atenção para a importância dos aspectos externos ao indivíduo, em especial, a relevância da comunidade linguística para o estabelecimento dos conteúdos de pensamento individuais, isso não implica, de modo algum, a redução da mente a algo externo a ela. Em outras palavras, a redução do pensamento à linguagem não deve ser confundida com a redução da mente à linguagem, e muito menos com alguma estratégia de eliminação dos aspectos internos e individuais da mente, em seu conjunto. 


\section{Conclusão}

Ao finalizar, gostaria de destacar aqueles que penso serem os principais limites do Externalismo Social, em relação às questões da mente. Ao privilegiar a origem externa dos conteúdos de pensamento, ou seja, dos conceitos, e ao definir o pensamento em termos de atitudes proposicionais, deixa-se de lado, ainda que não se negue a existência, como procurei mostrar, o aspecto qualitativo ou fenomênico das experiências subjetivas, intrínseco aos sentimentos e sensações externas e internas. Mas não seriam os sentimentos e sensações considerados em seu caráter fenomênico também formas de pensamento, como defendia Descartes e, nesse sentido, inseparáveis da intencionalidade? Não teria o pensamento conceitual também um caráter fenomenal? Julgo a resposta a essas questões importante, pois entendo, como já o frisei na introdução deste artigo, que elas nos remetem inevitavelmente aos problemas da natureza da mente e de sua relação com o corpo, como revela o exemplo paradigmático de Descartes.

Lynne Baker critica Descartes pelo fato de o filósofo, em sua visão solipsista, não levar em consideração a existência de comunidades sociais e lingüísticas, sem as quais não seria possível ser um indivíduo autoconsciente, pessoa nos termos da filósofa, ou seja, "[...] indivíduos capazes de refletir sobre si mesmos como si mesmos" (BAKER, 2011, p. 9). Estando sozinho no mundo, continua Lynne Baker, Descartes não seria capaz de ter pensamentos acerca de si mesmo, tais como perguntar se ele estaria ou não sonhando ou sendo enganado por um Gênio Maligno, pois não seria capaz de ter conceitos constitutivos de seu pensamento, tais como "Eu", "fogo" e "robe". Para Lynne Baker, "[...] a decisão de Descartes de olhar a si mesmo como não tendo 'mãos, olhos, carne, sangue, sentidos' não é um pensamento que Descartes poderia ter tido se ele tivesse sido verdadeiro: o fato de ele ter tido aquele pensamento garantiu que ele era falso. Solipsismo é uma fantasia dos filósofos" (BAKER, 2011, p. 9) Pode-se constatar que o foco principal dessa crítica a Descartes reside no modo de aquisição dos conteúdos de pensamento. Um "solitário Descartes" não poderia ter pensamentos com os conteúdos que ele tem, isto é, conceitos, os quais dependeriam de fatores externos a ele, o mundo externo material e, em especial, uma parte importante desse mundo, a comunidade linguística.

Penso que o próprio Descartes concordaria com essa tese. Primeiro, pelo fato de ele jamais negar a existência do mundo material e de outros seres humanos enquanto conteúdo de pensamento, ainda que coloque em dúvida o fato de esse conteúdo provir da existência real de coisas ou pessoas no mundo, já que poderia provir, por exemplo, da ação de um Deus Enganador. A esse respeito, cabe lembrar com Berkeley que é possível ser idealista ao mesmo tempo em que empirista. Segundo, Descartes defendia que, embora o pensar, em seus diferentes 
modos, constitua a essência do espírito ou substância pensante, a maior parte de seu conteúdo, ou seja, um grande número de sua ideias provém da relação com o corpo e, através do corpo, do mundo externo. Recordemos que, para Descartes $^{8}$, nós temos três tipos de ideias: as ideias inatas, quer dizer, aquelas que nos são colocadas ao nascer, tais como a própria ideia de Deus e as ideias matemáticas; as ideias adventícias, ou seja, aquelas que advêm da experiência, como a ideia de cavalo e a ideia de asa; e, por fim, as ideias fictícias, isto é, aquelas que são construídas pelo espírito como resultado de seu pensamento imaginativo, a partir das ideias provenientes da experiência, por exemplo, a ideia de cavalo alado. Cabe observar que, tanto para Descartes quanto para os racionalistas em geral, até mesmo as ideias inatas precisam da experiência do espírito no mundo para se tornarem conscientes. Parece-me, então, de acordo com o que afirmei, que Descartes corroboraria a tese externalista segundo a qual as características do ambiente do pensador determinariam "frequentemente" e "em parte" os conteúdos do pensamento. Mas isso não significa que, para Descartes, a atividade pensante, ou seja, os acontecimentos mentais sejam, enquanto tais, externos ao sujeito pensante. Penso ser claro que, para Descartes, os conteúdos dos pensamentos da mente devem em geral ser compreendidos relacionalmente, isto é, levando-se em conta o corpo e o ambiente externo natural e cultural, o que não significa que o pensamento seja em si mesmo uma atividade externa ao sujeito pensante. Como sabemos, para Descartes, o pensamento é uma atividade subjetiva consciente, ainda que seus conteúdos advenham em grande parte das contingências da relação entre alma, corpo e mundo.

Se, conforme procurei mostrar, ainda que o Externalismo Social enfatize o fato de que os conteúdos de pensamento, os conceitos, dependem da relação com fatores externos, em especial, da comunidade linguística, isso não significa a redução da mente nem ao corpo nem a fatores externos a ela e, muito menos, a sua eliminação. Como frisei em outra oportunidade, referindo-me à necessidade de separar a questão da explicação da origem do conteúdo do pensamento e de seu papel causal, ninguém duvida de que o pensamento, em virtude de seu conteúdo, afeta o que fazemos. Todavia, isso por si só não constitui uma solução para o problema da relação mente e corpo, o qual deriva inevitavelmente da distinção mente, corpo e mundo, problema que apenas se coloca desde o momento em que se reflete a respeito da natureza do pensamento e se o considera como distinto do físico e a ele irredutível. Sendo o caso, e me parece ser essa a

\footnotetext{
8 Estou aqui considerando o pensamento de Descartes resultante das seis meditações metafísicas. Chamo a atenção para esse aspecto, por entender que muitas críticas a Descartes são inapropriadas, por levarem em conta apenas o pensamento do filósofo na primeira e na segunda meditações. Privilegiam, assim, a separação mente e corpo, desconsiderando os resultados da união da mente com o corpo, ou seja, esquecem-se da sexta meditação e das "Paixões da Alma".
} 
posição do Externalismo Social, essa abordagem não deveria ser tomada como uma alternativa eficaz para o enfrentamento desses problemas filosóficos.

COELHO, Jonas Gonçalves. Social externalism: mind, thought, and language. Trans/ Form/Ação, Marília, v. 35, n. 1, p. 167-192, Jan./Abril, 2012.

\begin{abstract}
ABSTACT: My aim is to show that the externalist theses, "meanings are not in the head" and "thoughts are not in the head", do not necessarily imply the more extreme thesis that "the mind is not in the head". I consider this question in terms of the social externalism approach of Tyler Burge and Lynne Baker, arguing that the importance these thinkers attribute to language in questions relative to the mind does not mean either the reduction of the mind to language or the elimination of the mind. My conclusion is that social externalism is not an efficient strategy for dealing with problems of the nature of the mind or the relationship between mind and body.
\end{abstract}

KEYWORDS: social externalism; Lynne Baker; Tyler Burge; mind; thought; language.

\title{
REFERÊNCIAS
}

BAKER, Lynne R. First-Person Externalism. The Modern Schoolman, LXXXIV, 155-170, January \& March, 2007a.

. Social Externalism and First-Person Authority. Erkenn, 67, 287-300, 2007b.

- How to have Self-Directed Attitudes. In: SCHMID, Hans Bernhard; ZIV, Anita Konzelmann; GLOOR, Juliette (Ed.). Self-Evaluation: Individual and Collective. Springer Publishing, Forthcoming, 2011.

BURGE, Tyler. Individualism and the Mental. Studies in Metaphysics. Midwest Studies in Philosophy, IV, p. 73-119, 1979.

. Other Bodies. Thought and Object. Essays on Intentionality. Oxford, Clarendon, p.97120, 1982.

Individualism and Psychology. The Philosophical Review, XCV, n.1, January, 1986. . Individualism and Self-Knowledge. Journal of Philosophy, 1988.

$\overline{322,1989}$.

Individualism and Causation in Psychology. Pacific Philosophical Quartely, 70, p. 303- 
COELHO, J. G.

Origins of objectivity. New York: Oxford University Press, 2010.

COELHO, Jonas. A Causação Mental Segundo o Realismo Prático de Lynne Rudder Baker. Cognitio-Estudos: Revista Eletrônica de Filosofia. V. 7, N. 2, dezembro, 2010.

PUTNAM, Hillary. Meaning and Reference. The Journal of Philosophy. Vol. 70, no 19, 1973. The meaning of "Meaning". Language, Mind and Knowledge. Minnesota: Minnesota University Press, p. 131-193, 1975.

Recebido em: 03.10.2011

Aprovado em: 09.12.2011 